\title{
Longevidade: Cidadania, Participação e Direitos Sociais
}

Longevidad: Ciudadanía, Participación y Derechos Sociales

Longevity: Citizenship, Participation and Social Rights

Isabel Maria Gomes de Oliveira

Faculdade de Psicologia de Ciências da Educação da Universidade do Porto - Porto - Portugal

Maria da Luz Cabral

Escola Superior de Saúde do Alcoitão - Alcabideche - Portugal

\section{RESUMO}

A longevidade é sem dúvida uma das maiores conquistas da humanidade. O aumento do número de pessoas nos grupos etários mais elevados (+65) é essencialmente, fruto de um conjunto de políticas públicas e sociais, que nas últimas décadas foram implementadas em Portugal e que originaram a redução da mortalidade e consequentemente o aumento da longevidade. Ao mesmo tempo, desencadeou grandes desafios legislativos na efetivação de políticas públicas que protejam os direitos sociais e políticos. Enquanto cidadãos de pleno direito, compete ao Estado a garantia dos mesmos, promovendo o direito à cidadania, dignidade, participação cívica na sociedade.Este artigo surge a partir de um trabalho de investigação realizado com pessoas de idade avançada ${ }^{1}$ num lar residencial, onde se refletiu sobre os sentidosque estes atribuem à cidadania e à participação, agora que estão na condição de "reformados", "aposentados" e "institucionalizados".

Palavras-chave: Envelhecimento. Longevidade. Cidadania. Participação e Direitos Sociais.

\section{RESUMEN}

La longevidad es sin duda una de las mayores conquistas de la humanidad. El aumento del número de personas en los grupos de edad más elevados $(+65)$ es esencialmente el fruto de un conjunto de políticas públicas y sociales, que en las últimas décadas se han implementado en Portugal y que han originado la reducción de la mortalidad y consecuentemente el aumento de la longevidad. Al mismo tiempo, desencadenó grandes desafíos legislativos en la efectividad de políticas públicas que protejan los derechos sociales y políticos. Como ciudadanos de pleno derecho, corresponde al Estado la garantía de los mismos, promoviendo el derecho a la ciudadanía, dignidad y participación cívica en la sociedad. Este artículo surge de un trabajo de investigación realizado con personas de edad

\footnotetext{
${ }^{1}$ OMS, 2015: 3
}

PSI UNISC, Santa Cruz do Sul, Vol. 1, n. 1, jul./dez. 2017, p.<18-31>. 
avanzada en un hogar residencial, donde se reflejó sobre los sentidos que éstos atribuyen a la ciudadanía ya la participación, ahora que están en la condición de "reformados", "jubilados" y " Institucionalizados".

Palabras clave: Envejecimiento. Longevidad. Ciudadanía. Participación y Derechos Sociales.

\begin{abstract}
Longevity is undoubtedly one of the greatest achievements of mankind. The increase in the number of people in the highest age groups $(+65)$ is essentially due to a set of public and social policies, which in the last decades were implemented in Portugal and which led to a reduction in mortality and consequently an increase in longevity. At the same time, it has unleashed major legislative challenges in the implementation of public policies that protect social and political rights. As citizens with full rights, it is the responsibility of the State to guarantee them, promoting the right to citizenship, dignity and civic participation in society. This article is based on a research project carried out with elderly people in a residential home, reflecting on the meanings they attribute to citizenship and participation, now that they are in the condition of "retired", "pensioners" and "Institutionalized".
\end{abstract}

Keywords: Aging. Longevity. Citizenship. Participation and Social Rights.

\section{Introdução}

O envelhecimento, na sociedade portuguesa, é frequentemente associado a uma fase específica do ciclo de vida, a idade da passagem para a situação de reforma, sendo esta relacionada como o anúncio do início da velhice (Squire, 2005: 14). A reforma é um dos acontecimentos de vida mais significativo do ciclo de vida das pessoas, e representa a saída do mercado de trabalho, da participação ativa na esfera pública, o que acarreta desafios e mudanças ao nível quer dos rendimentos, quer dos papéis sociais destas pessoas. Apesar de ser um processo dinâmico, progressivo e irreversível, acompanha o ser humano desde o dia do seu nascimento. O envelhecimento é um processo que não afeta todos de igual modo, e está associado a um conjunto de alterações biológicas, psicológicas e sociais que ocorrem ao longo do ciclo vital de cada pessoa.

As eventuais reduções da capacidade funcional das pessoas de idade avançada remetem para situações de vulnerabilidade familiar ou para a institucionalização, e tal nãopode justificar a sua exclusão de uma efetiva participação na vida social, política, económica e cultural. A OMS, 2015 refere que "a idade avançadafrequentemente envolve mudanças significativas além das perdas biológicas (...) incluem mudanças nos papéis e posições sociais, bem como na necessidade de lidar com perdas de relações próximas." (OMS, 2015:12). Assim, o envelhecimento e a longevidade devem ser olhados como uma mais-valia, sendo necessária a criação de políticas públicas de proteção social adequadas, que promovam uma maior dignidade, incentivem a coesão, a interação familiar e naturalmente a solidariedade intergeracional promotoras de bem-estar.

A Organização Mundial da Saúde (OMS) olha o envelhecimento numa perspetiva multidimensional,integrando diferentes domínios da vida pessoal e social, através de processos de "otimização das possibilidades de saúde, de participação e de segurança, a fim de aumentar a qualidade de vida durante a velhice" (OMS, 2002: 3). Considerando que se devem promover condições que incitem o seu potencial para o bem-estar físico, psicossocial ao longo do curso de vida, a participação ativa na sociedade deve ser conforme com as suas necessidades, interesses e capacidades.

Na senda de Marques (2011) envelhecer não é ser velho, é ir sendo mais velho dentro de um processo complexo de desenvolvimento que 
ocorre entre o nascimento e a morte, e é inerente a todos os seres vivos. Ser mais velho implica a passagem do tempo e a quantidade de anos que se vive. Todo o ser humano nasce, cresce, logo envelhece, num processo constante que não se reduz apenas a perdas, mas a uma interação contínua de fenómenos biológicos, psicológicos e sociais que provocam alterações no corpo à medida que a idade cronológica vai aumentando.

O direito e o exercício da cidadania são pressupostos inadiáveis de um Estado verdadeiramente democrático, pelo que a participação dos cidadãos, independentemente da sua idade, status ou situação em relação ao trabalho, surge como umacondição necessária à construção e desenvolvimento de uma sociedade cívica, sustentável e participativa. Tendo em conta estes pressupostos, iremos refletir, a partir de um trabalho de investigação realizado num lar residencial para pessoas de idade avançada, o modo como o envelhecimento demográfico, enquanto fenómeno social, tem subjacentes questões da cidadania, de inclusão ou exclusão (participação), e o modo como estes cidadãos percecionam essa condição, agora que estão na condição de "reformados" e "institucionalizados".

Este artigo surge da análise dos ditos dos nossos interlocutores (pessoas de idade avançada e institucionalizadas), nas conversas/tertúlias realizadas com o grupo alvo, a partir dos conceitos de cidadania, participação, pessoa, inclusão/exclusão...na sua relação com o pleno exercício participativo. Estes temas foram abordados de um modo reflexivo, tendo em conta as suas próprias vivências enquanto pessoas de idade avançada e o modo como vivem a sua participação na esfera pública, enquanto cidadãos detentores de direitos,e que pela sua condição vivem institucionalizados.

A metodologia utilizada baseou-se na técnica de investigação social Focus Group e em notas de terreno, elaboradas durante as sessões realizadas. A escolha desta técnica favoreceu uma maior interação entre o grupo e os sujeitos de investigação, pela possibilidade de introduzir discussões flexíveis, que permitiram captar as interações e dinâmicas entre os intervenientes, as manifestações de partilha de experiências, pensamentos e emoções e a pertinência de um sentimento coletivo. Ou seja, durante as sessões realizadas, deparamo-nos com discursos produzidos que geraram outros discursos, potenciando formas de pensamento e um lugar de pertença.

Neste propósito "os comentários dos participantes foram utilizados numa perspetiva qualitativa e no contexto de produção, evitando o enfoque no indivíduo isolado e desligado da interação com as outras pessoas, o que permitiu valorizar a tomada de consciência" (Macedo, 2009: 167). O material recolhido foi analisado através da técnica de análise de conteúdo, que permitiu tratar os dados recolhidos de "uma forma metódica" (Quivy e Campenhouldt, 2008: 227).

\section{"Ser idoso é lutar o tempo todo para ser pessoa"}

um dos critérios pelo qual se pode aferir o índice de humanização duma sociedade é o lugar e tratamento reservado às pessoas idosas, pois envelhecer é uma inevitabilidade do ser humano. (Oliveira, 2010:194)

A demografia em Portugal tem sofrido alterações significativas ao longo dos anos, tendo-se registado um decréscimo no número de nascimentos e, em simultâneo, um aumento do número de pessoas de idade avançada igual ou superior a $65 \operatorname{anos}^{2}$, resultado do aumento da esperança média de vida e da melhoria das condições de vida, do apoio social e de assistência.

O envelhecimento demográfico, resultante do desenvolvimento socioeconómico, é um fenómeno social patente nas sociedades modernas e nas democracias maduras, originando o aumento da longevidade e, assim, um prolongamento da faixa etária entre a

\footnotetext{
${ }^{2}$ OMS, 2002
} 
terceira e a quarta idade. Assiste-se, hoje, a um fenómeno social do envelhecimento da população, consequência da melhoria das condições de vida ao nível médico-sanitário, da higiene e da alimentação. No entanto, este nem sempre equivale a um indicativo de bem-estar e/ou autonomia que permita às pessoas de idade avançada uma vida que coincida com os seus interesses, necessidades e/ou expectativas. Com o crescimento destas faixas etárias, aumenta a necessidade de proteção social, exteriorizandose de forma integral e diferenciada, consoante esta se dirija à família como um todo, ou às necessidades específicas dos seus membros, decorrentes da idade, do estado de saúde e da condição socioeconómica. Este fenómeno concorre com o aparecimento de uma rede de cuidados de resposta social e/ou de saúde, faz emergir renovadas categorias profissionais como resposta às necessidades, cada vez mais evidentes, da pessoa mais velha.

A longevidade é uma conquista da humanidade, devida aos avanços técnicos na saúde, à melhoria da condição económica da população em geral e traduz-se num desafio para as sociedades. Ao refletirmos um pouco acerca da história da Humanidade, verificamos que a velhice foi sempre objeto de construção social e extensiva à cultura e à organização social das diferentes civilizações. As conotações atribuídas à "velhice" e às atitudes para com os "velhos" são sempre produto de uma cultura, historicamente moldada segundo as interpretações dominantes acerca da mobilização do corpo humano, da divisão social do trabalho e não porque ela exista em si,como preconceito etarista na relação entre velhos e novos.

A sociedade industrial, ao incidir em versões mais ou menos sofisticadas de conceções etnocêntricas e em grupos, presumidamente de padrões ideais, reduz $o$ desenvolvimento humano, contribui para que a velhice seja considerada socialmente como um período de declínio e encarada como uma etapa marginal e não normal da vida, fazendo emergir preconceitos e estereótipos que definem as imagens das pessoas de idade avançada na sociedade "afluente". Encarar a velhice em todas as suas vertentes, numa sociedade em que a cultura da ancianidade aparece como o resto que sobra nas margens da sociedade industrial, conduzida pela vontade do poder, de produzir, de consumir e pela relativização de todos os valores, constitui uma realidade, sobre a qual todos devemos refletir e debater, de modo a desconstruir os mitos e as imagens existentes e que se encontram ligados aos estereótipos de comportamento adequado a esta faixa etária.

A velhice considerada como um problema social e de saúde pública, não existe. $\mathrm{O}$ que existe são as transformações que o duplo envelhecimento da população suscita nas regulações centrais da sociedade, ao colocar em jogo o equilíbrio económico e social. Pois sendo este um grupo social fragilizado, está também ele, muito mais suscetível à condição de pobreza, como afirma Alfredo Bruto da Costa (1998: 53) "o pobre pode ser definido como alguém totalmente destituido de poder." Combater a pobreza implica devolver o poder político, económico, social e cultural ao pobre. No caso das pessoas de idade avançada refere que

A situação [das pessoas de idade avançada], além de constituir já um problema grave, tende a agravar-se, designadamente como o progressivo envelhecimento e as mudanças sociais que ocorrem sobretudo no mercado de trabalho." Sendo necessário reconhecermos que este é um grupo social, maioritariamente pobre e que essa condição "é marcada pela total ausência de poder, ao ponto de nem sequer ter poder para reivindicar os seus direitos mais elementares (Costa, 1998: 53).

A "ideia" de mais velho, não é fácil de assumir, nem agradável de perspetivar. Apesar dos constrangimentos que a sociedade atual possa suscitar à velhice, a verdade é que como fenómeno pessoal, todos nós sentimos que, se sobrevivermos, ela é o nosso destino. 


\section{Direitos, Deveres e Cidadania: Da cidadania atribuída à cidadania reclamada}

"é isto, aquilo e aquele outro"

Falar de cidadania implica saber reconhecer o que essa palavra representa na vida dos sujeitos do nosso grupo de investigação, não a banalizando num mero objeto fora dos contextos sociais, políticos e económicos, aos quais eles se reportam.Não podemos falar de cidadania sem falarmos de cidadãos, e ser cidadão de acordo com Le Robert appud Perrenoud (2005:2) é "a qualidade de cidadão".

Ser cidadão é um conceito socialmente construído, e que ao longo dos tempos se foi alterando. $\mathrm{Na}$ antiguidade ser cidadão era a pertença a uma nação, com a revolução francesa o conceito alterou-se e passou a ser "outorgada automaticamente na idade da "maioridade civil" [inicialmente aos homens autóctones, depois às mulheres e aos residentes]"os direitos e as obrigações decorrentes da condição de cidadão estão ligados ao seu vínculo a uma comunidade particular (...) sendo preciso preparar para ser bons cidadãos todos aqueles que se tornarão "simples cidadãos" sem nada terem pedido" (Perrenoud, 2005:20-21).

Para este autor, o bom "cidadão" é aquele que respeita e convive em harmonia com os outros, e pela educação adquire as ferramentas necessárias, para reclamar os seus direitos e exercer os seus deveres.Para, T.J. Marshall (1967) a cidadania é

(...) um status concedido aqueles que são membros integrais de uma comunidade. Todos aqueles que possuem o status são iguais com respeito aos direitos e obrigações pertinentes ao status (...)." no qual "todos (...) são iguais com respeito aos direitos e obrigações. (Marshall, 1967: 76)

Ou seja, para este autor a cidadania é tudo que vai desde o direito a um mínimo de bem-estar económico e segurança, até ao direito de participar na sociedade. Podemos considerar esta definição vaga, porque se refletirmos sobre o que é ser um "membro integral" de uma comunidade, verificamos que varia de acordo com os valores de uma determinada sociedade.

Nas sociedades ocidentais e de um modo geral, podemos considerar que a cidadania é vista, pelo menos teoricamente, como um status universal e tem em conta três tipos de direitos - civis, políticos e sociais bem como os direitos e deveres a eles associados. Neste ponto, este autor considera que a educação enquanto direito social de todos os cidadãos, é fundamental para a tomada de consciência dos direitos civis, para o exercício dos seus direitos políticos e para que reivindiquem os seus direitos sociais. $\mathrm{O}$ autor Estevão (1997) refere que a construção da cidadania está dependente das novas conceções de Estado e do mercado, que este é um conceito que inclui todas as relações sociais entre os indivíduos e o Estado e os indivíduos entre si e que todas as formas de cidadania "têm em comum a abordagem da relação entre os cidadãos e os setores sociais mais amplos, com ênfase particular na participação dos cidadãos em esferas da vida pública" como refere o autor (Estevão, 1997: 613).

O direito social é o mais relevante na nossa investigação, pois refere-se ao direito mínimo de bem-estar económico, à segurança, ao direito de participar, configurando um tipo de cidadania que apresenta uma dimensão legal estruturada, que permite aos indivíduos um mínimo de segurança e de proteção social e tal como refere um dos nossos investigados:

“...) temos o direito pelos nossos
descontos e como cidadãos livres que
somos, de ter um resto de vida feliz, ou
uma velhice feliz. (...) Eu acho que as
instituições estão muito mal... nenhuma
instituição funciona bem, [ou são] bem
administradas não sei se é a palavra
correta. Eu não digo nada porque se vou
a dizer, a fulana é malcriada (...)"
(extrato do focus group)

“(...) temos o direito pelos nossos descontos e como cidadãos livres que somos, de ter um resto de vida feliz, ou uma velhice feliz. (...) Eu acho que as instituições estão muito mal... nenhuma instituição funciona bem, [ou são] bem administradas não sei se é a palavra correta. Eu não digo nada porque se vou a dizer, a fulana é malcriada (...)" (extrato do focus group) 
Pela voz dos nossos investigados damonos conta daquilo que designamos como cidadania atribuída e cidadania reclamada, e na senda de Stoer e Magalhães (2005), surgem pelos processos de globalização e da necessidade de se reestruturar os processos identitários dos sujeitos. Assim, nesta "pósmodernidade" (idem: 119), passamos de uma "cidadania atribuída" (idem: 93) outorgada pelo Estado-Nação da modernidade, para uma "cidadania reclamada" (idem: 95) por parte de diferentes grupos sociais, entre eles o grupo das pessoas de idade avançada. $\mathrm{Na}$ cidadania atribuída, o que estava em jogo era a igualdade política, social e cultural, na cidadania reclamada, o que está em causa é o direito do sujeito à diferença, o direito a ter voz, o direito à pluralidade, Marshall (1967) Stoer e Magalhães (2005:83), consideram que o trabalho da escola/educação é fundamental neste processo.

As formas emergentes de cidadania são cada vez mais caraterizadas pela reflexividade (Giddens, 1990), pelo que não é apenas uma questão de atribuição, pelo facto de se pertencer a um Estado-nação, mas pelo contrário ela emerge pela sua reclamação.

Com a emergência da cidadania «reclamada»e «reivindicada», e visto que a sua origem tem a ver com o carácter «incompleto» da cidadania atribuída através do contrato social moderno, o locus da determinação de quem é diferente pluralizou-se (...) A falta de «plenitude» da cidadania atribuída deriva da sua incapacidade intrínseca de traduzir reconhecimento em cidadania participativa. (Stoer, 2008: 224).

A pós-modernidade veio trazer um nova perspetiva, uma nova ontologia social, e com ela surgiram mudanças no modo como as relações sociais, entre os grupos e os indivíduos eram legitimadas. Ao contrário da modernidade, na pré-modernidade o corpo social não é homogéneo, como tal os projetos de cidadania têm que ser repensados tendo em conta a sua identidade e o grupo de pertença.
No grupo em questão e tendo em conta a sua vulnerabilidade física, social, cultural e económica, as questões de uma cidadania atribuída ou reclamada é condicionada, pelo receio de sofrerem represálias, isto apesar do grupo ter consciência dos seus direitos, no entanto pela sua voz damo-nos conta que existe o receio do seu exercício:

\section{(...) Dizem aquele utente boa pessoa é tão exigente e eu pergunto, porque é que ele não pode ser exigente, se na vida passada na sua casa com as suas coisas era exigente? Porque não pode agora ser exigente das coisas que necessita, é isso, e outras mais. (...) - Pois, outra coisa que eu e mais uma amiga, já pensámos escrever lá o que é preciso e outras coisas, mas lá está aquilo vai para uma reunião, passa para os setores de que a gente se queixou e é uma chatice, sabe? (...) (extrato do focus group)}

O processo de envelhecimento está sujeito a mudanças e a transformações, perdas e ganhos, que influenciam o modo como as pessoas de idade avançada se revêm na sociedade, acentuando as suas fragilidades e incapacidades na defesa dos seus direitos, o que contribui para uma perda de respeito e de cidadania.

A cidadania é um projeto de vida social, ser "cidadão é uma forma expandida de ser sociável, constituída por inúmeras relações libertadoras, criativas e respeitosas com os outros (...)" (Sacristän, 2003: 200).

\section{Perceção, Vida Ativa e Reforma: Cidadão e a Condição para Ser}

"O trabalho e a cidadania: o trabalho como condição para se ser" 
Ser parte de uma comunidade é necessidade constante da condição humana. Sempre que uma pessoa não se sente como parte integrante do meio social em que está inserido, nas suas múltiplas vertentes, sentir-seá sempre excluído, estará sempre à margem, será sempre um estranho.

os processos que subjazem à construção das identidades decorrem no quadro das relações de poder que diferenciam dominantes e dominados, maiorias e minorias, quer se trate de poder económico, político ou simbólico (...). As relações e interações que os indivíduos constroem prendem-se com o lugar que ocupam no espaço social. Este lugar é resultado da combinação de diferentes capitais (económico, social, cultural e simbólico) de que são possuidores. (...) Privilegiam-se determinadas aproximações (...) Desenvolvem-se solidariedades, (...) (Saint-Maurice, 1997: 31-34).

Stoer e Magalhães (2005) referem que "a atribuição de cidadania aconteceu, num primeiro momento, sobretudo a nível formal, pois a determinação de quem se incluía no âmbito do contrato era feita a partir da posição dos indivíduos no mundo do trabalho" (Stoer e Magalhães, 2005: 83).

Do mesmo modo,também os nossos investigados afirmam que enquanto cidadãos ativos, tinham mais direitos do que aqueles que agora lhes atribuem,

"(...) Porque as coisas deveriam ser feitas de maneira diferente, para que nós fossemos mais bem servidos e elas tivessem uma melhor maneira" (extrato do focus group).

A "atribuição de cidadania, pelo contrato social moderno, era um ato fundado na legitimidade dos aparelhos do estado enquanto guardião da nação" (Stoer e Magalhães, 2005: 89) e estes cidadãos enquanto residentes de uma instituição que está sob a alçada do Estado sentem que não estão a ser devidamente protegidos os seus direitos.

No pressuposto do que até aqui era "verdade" e norma, atribuição de um direito pelo facto de serem todos cidadãos de um mesmo Estado, passa agora por ser uma falácia. E estes cidadãos estão sujeitos a variadas formas de exclusão social, que se refletem em diversas dimensões, tendo efeitos em diferentes "lugares" da vida de cada indivíduo, em determinado contexto em que cada sujeito é sujeito, ator social, em "contextos de agência social" (idem: 58), funcionando num dado "nível" (idem: 67) dentro do continuum que vai do local ao global.

A reflexão sobre estes "lugares" (idem: 67) onde indivíduo e sociedade interagem, onde os projetos pessoais se desenvolvem condicionados pelos constrangimentos impostos pela sociedade, e que motivam ou geram processos de exclusão/inclusão social, ajuda-nos a compreender a vulnerabilidade em que alguns grupos sociais se encontram.

Os processos de vulnerabilidade e de exclusão social estão, não raras vezes, a montante dos processos de conflitualidade social e de marginalidade comunitária. As características de vulnerabilidade podem ser também enunciadas como um processo multidimensional, análogo às desigualdades sociais e consequentemente à exclusão social. O domínio de desigualdades sociais, de vulnerabilidades e de pobreza, no grupo das pessoasde idade avançada converte-se num misto de risco e de limite.

A definição de velhice não é clara e reflete ideologias que a moldam. Lenoir (1989) refere que a construção social do conceito de velhice ao inscrever-se numa conjunturalidade histórica, tem "por base os valores de cada sociedade, concordantes com a hierarquia de posições sociais dos indivíduos na estrutura económica e social, sistematizados numa noção de pessoa" (Lenoir, 1989: 67) e é sobre isto que o nosso grupo de investigados nos fala, que os seus direitos eram mais garantidos quando trabalhavam: 
Eram mais, eu acho que agora tinham de continuar a ser... ou pelo menos continuar ainda, porque já vivemos $e$ fizemos a nossa vida ativa, e é termos o direito pelos nossos descontos e como cidadãos livres que somos de ter um resto de vida feliz, ou uma velhice feliz... [agora] é menos, é menos não há dúvida nenhuma, por mais tempo(...) (extrato do focus group)

\section{Idadismo, Consciência Social e Sociedade: Qual o lugar que a pessoa idosa ocupa em termos de cidadania?}

\author{
"O novo $e$ o velho (...)" $a$ \\ ambiguidade de ser
}

As expressões velhice e velho ao refletirem um significado pejorativo foram substituídas por Terceira Idade e Idosos, para não ofender o pudor social. Estas são expressões anacrónicas que não existem por si mesmas, e sendo construções sociais são igualmente portadoras de uma cultura, pois o que existe é o ser humano pleno a caminho da sua auto-realização, como pessoa humana, como indivíduo inimitavelmente único e como cidadão.

A velhice é um conceito abstrato, uma categoria socialmente construída e como escreveu Simone de Beauvoir (1990) é o que serve para referir o período de vida em que as pessoas ficam velhas. Esta forma de dizer, denuncia um olhar holístico que visa propiciar condições para uma mudança de perspetiva em torno do fenómeno, sobretudo porque as diferenças individuais coexistem com a velhice o que contradita a tendência da sociedade atual em homogeneizá-la num único grupo etário normativamente iniciado aos 65 anos de idade. Saul Karsz (1988) define velhice como "representação ideológica sob a qual as pessoas cronologicamente idosas são reconhecidas enquanto ilustrações animadas da velhice e por outro lado desconhecidas enquanto sujeitos de desejos inscritos em classes sociais" (Karsz, 1988: 37).

A construção social da velhice foi alterando ao longo dos tempos o seu significado, valor e função social, e na senda de Anne - Marie Guillemard (1980), ela pode ser definida de acordo com novos conceitos de velhice:

- Velhice Invisível, inerente às Sociedades Tradicionais Ocidentais, em que a condição de ser velho estava associada à função patrimonial (séc. XIX e início do séc. XX). A solidariedade para com os idosos era familiar, privada e realizada no espaço doméstico.

O espaço público (instituições e lares) destinava-se à velhice desprotegida. $\mathrm{O}$ envelhecer não era condição para aquisição de um novo estatuto social.

- Velhice Visível, inscrita nas Sociedades Industriais e pós Industriais.

Nesta sociedade existe um modelo forte de estratificação, segregação etária, de acordo com o ciclo produtivo e na construção social do grupo de "idosos" associada à reforma.

A velhice visível, na senda de Giddens (1992) é uma das consequências da modernidade, resultante das transformações que ocorreram nas sociedades industrializadas e das condições para que socialmente se começasse a equacionar a velhice, como uma situação problemática a necessitar de resolução coletiva.

A velhice como problema social é um produto da construção social resultante do confronto de ideias e de interesses entre grupos sociais e entre gerações de modo a obter poder de manipulação sobre as classes de idades, pois como nos dizem os nossos investigados:

"Esta gente é nova e ainda não deve ter sentido muito, eu é que já sou velhota” "vinha para o lar tratar de velhinhos e não..."

"As pessoas com mais idade de que eu com certeza..." (extrato do focus group)

Este extrato reflete o modo como os nossos investigados percecionam o ser velho na atualidade e na comunidade onde vivem, tendo em conta o lugar que ocupam. 
A respeito do entendimento das especificidades e características multidimensionais deste grupo etário, e se tivermos em conta as políticas assentes na inclusão/exclusão social, remetemos para Stoer e Magalhães (2005).

Falar de exclusão social é falar simultaneamente de inclusão social, (...) estes conceitos são enquadrados no âmbito da problemática da equidade e da problemática do conhecimento e atuam como mapa para compreender como é que as políticas são postas em prática. (idem: 66)

Parece importante referir que estas (inclusão/exclusão) são conceptualizadas como sendo duas entidades diferentes nas quais o objetivo é produzir inclusão e eliminar a exclusão com base no preconceito etarista (idem:66).

A forma propícia de incluir a diferença social torna-se uma questão central no desenvolvimento de novas formas de suprir vulnerabilidades. Quando falamos de diferença num contexto social como o atual, que sofre elevadas pressões de globalização, é inevitável falar também de inclusão e de exclusão. Deste modo, estes conceitos são indissociáveis pois "a exclusão (...) é permanentemente comparada com um cenário de algo que está incluído" (Popkewitz e Lindblad, 2000 in Stoer \& Magalhães e Rodrigues, 2004: 27), "mas que a exclusão social tem uma origem sobretudo sociocultural."

A alteração demográfica originou a mudança na solidariedade e na interdependência das gerações e classes que, de algum modo, estavam na base de funcionamento do Estado, colocando em causa os mecanismos de financiamento e de sobrevivência do Estado Providência.

A política social procura colmatar as desigualdades sociais, principalmente no grupo de maior vulnerabilidade, sendo este um grupo constantemente excluído, ora do mundo de trabalho pela sua idade (consequentemente menor importância social), ora pela falta de poder de consumo (baixos rendimentos, baixo consumo), são também excluídos da retaguarda familiar (fragilizada e/ou nula). E citando Fonseca (2006),

uma das causas mais graves associadas ao idadismo consiste no facto dele suscitar uma atitude negativa que afeta o comportamento dos mais novos em relação aos mais velhos e que pode fazer, inclusive, com que os próprios idosos olhem para si mesmos de acordo com uma imagem socialmente construída, conforme às expectativas generalizadas, isto é, incompetentes e incapazes. (Fonseca, 2006: 28)

Esta debilidade é fomentada pela economia de mercado e pela inexistência efetiva de um Estado Providência com poder de regular os deficits dos cidadãos. E este conceito está de tal forma enraizado na nossa sociedade, que por um lado se teme envelhecer e se tenta não parecer velho, para não se tornar incompetente e incapaz aos olhos dos outros, e por outro tratam-se as pessoas de idade avançada como crianças e como apenas dignos de papéis sociais de menor relevo.

Está-se perante uma forma de dominação institucionalizada com a dimensão simbólica que põe em ação estruturas cognitivas suscetíveis de serem aplicadas a todas as coisas do mundo e, em particular, às estruturas sociais, como escreve (Bourdieu, 1998: 20).

Assim, as pessoas de idade avançada são excluídas da vida social, política e económica com base nos interesses económicos de produção que provocam o conflito entre os jovens e as pessoas em idade ativa, na conquista de postos de trabalho ocupados pelas últimas, desvalorizando-se constantemente as capacidades e o potencial de realização que permanecem na maioria destas pessoas.

\section{A pobreza neste grupo social... "Menos por direito!"}

A "pobreza" é um fenómeno complexo que significa coisas diferentes para diferentes pessoas. A relevância do conceito depende 
basicamente do nível de vida e da forma como, numa dada sociedade, são atingidas as diversas necessidades humanas. Embora também possamos referir que uma inadequada inserção social, e a ausência de poder e dependência psicológica e económica, estejam estreitamente associadas à pobreza.

Paugam (2003) refere que "nas sociedades modernas, a pobreza não é somente o estado de uma pessoa que tem falta de bens materiais, corresponde também a um estatuto social específico, inferior e desvalorizado que marca profundamente a identidade dos que a experimentam" (Paugma, 2003:23).

A pobreza como último reduto a que estão destinados surge como uma dimensão da exclusão social, e é causa efeito da negação total ou parcial de direitos humanos a nível global. Esta, no entanto é uma questão de justiça global, de consciência cívica e se nos reportarmos à declaração dos direitos humanos, verificamos que para os grupos dos pobres e dos que estão nas margens da sociedade, esta é uma fraude. Pelo que, falar de pobreza não é só falar de alguns grupos ou classes na sociedade, como o grupo das pessoasde idade avançada.

Falar de pobreza é falar de exclusão social, pois nesta situação verifica-se uma acentuada privação de recursos materiais e sociais, arrastando "para fora ou para a periferia da sociedade [todos/as que] não participam dos valores e das representações sociais dominantes", como refere o autor, Fernandes (1995: 14), o que contribui para que incorporem sentimentos de auto-exclusão, pois "tende a ser excluído todo aquele que é rejeitado de um certo universo simbólico de representações, de um concreto mundo de trocas e transações sociais" (Idem, 1995: 17). No caso do grupo social das pessoas de idade avançada a dimensão da exclusão resulta pela transformação da sua identidade, marcada significativamente por sentimentos de inutilidade e incapacidade de superar as dificuldades e os processos que contribuem para a sua exclusão, pois como os mesmos nos referiram, sentem "que não têm voz" "que não servem para nada".
Falar de pobreza é o mesmo que falar de exclusão social, é falar de multidões, de números, de pessoas que não têm voz e, por isso, invisíveis (tantas vezes arrumados/institucionalizados). Falamos de cidadãos a quem é negada a sua dignidade individual.

Assim, parece importante referir que a violação da dignidade humana é o princípio para que grupos de cidadãos sejam impedidos de direitos básicos, confrontando-os com situações de vulnerabilidade, como a pobreza, e impedindo-os de ultrapassar esta situação estrutural e conjuntural. Pelo que estes grupos se situam ou estão num processo de desligamento da sociedade circundante e, em muitos casos, das suas próprias famílias, condicionados por isso à exclusão social.

Neste quadro social e ideológico os indivíduos adquiriram práticas de distanciação do Estado, optando pelo não exercício da sua cidadania e desenvolvendo um olhar atomizado para os seus interesses, desencadeando mecanismos de estagnação, conformismo e aceitação das suas baixas condições de vida.

Não raras vezes, estas violações dos direitos sociais e políticos são fruto das ações/omissões das políticas e da legislação existente nos Estados, bem como nas políticas supranacionais emanadas pelas agências internacionais, que determinam/condicionam "hegemonicamente" as políticas públicas sociais dos Estados.

As políticas sociais são programadas numa lógica de compensação da condição de pobreza, ao mesmo tempo que aliviam as consciências de quem detém o poder de intervir num fenómeno que é estrutural. Desta forma, a abordagem conjuntural é de cariz paliativo, ou seja, as concretizações desta abordagem são-no numa lógica assistencialista/carencialista, que não procura global e estruturalmente a abolição/erradicação da pobreza.

Neste sentido, a legislação produzida para "combater" a pobreza proclama a igualdade de direitos e o combate à exclusão 
social, mas no entanto não passa de falácias, dado que no cerne da questão está a má distribuição da riqueza nacional e global (redistribuição da riqueza). Em 1950 Marshall dizia a este propósito, tal como conferem os autores Stoer e Magalhães (2005) que a cidadania social,

desenvolve-se na base de uma redistribuição económica identificada com o Estado de bem-estar. A justiça social depende de um Estado pró-ativo, no que diz respeito a uma redistribuição da riqueza baseada no princípio da igualdade de oportunidades, um dos pilares da democracia representativa (Stoer e Magalhães, 2005:95).

A este propósito, estes autores concluem que a cidadania reclamada é simultaneamente dependente de políticas de redistribuição, reiterando que não há qualidade sem que as questões da quantidade estejam minimamente resolvidas.

A política económica origina a pobreza e a política social alivia-a. Este tem sido o meio pelo qual se ampliam as desigualdades sociais, por isso importa referir que esta questão se inscreve na redistribuição de rendimentos e que, na atualidade, a pobreza não é só insuficiência de recursos económicos. A pobreza relativa, é um processo socialmente construído, um "estado" associado a carências/escassez de recursos económicos, enquanto a exclusão social diz respeito a uma área mais abrangente de privação, à qual a pobreza se associa enquanto dimensão originária.

A preocupação, no nosso entender, é exatamente o lugar que a sociedade estipula para os grupos de pessoas/cidadãos que estão na condição de pobreza, atendendo ser uma relação à reação social resultante da situação especifica.

Boaventura Sousa Santos refere que Portugal tem um Estado Providência fraco, que coexiste com uma sociedade providência forte ou seja o Estado, tendo em conta o seu défice de providência, vai sendo compensado pela providência social produzida.

Esta sociedade de providência segundo o mesmo autor "pretende designar redes de relações de interconhecimento, de reconhecimento e de entreajuda baseadas em laços de parentesco e vizinhança. (...) Numa base não mercantil e com lógica de reciprocidade semelhante à da relação de domínio estudada por Marcel Mauss." (Santos, 1991: 37). Reiterando que a sociedade providência é, como refere Bourdieu (1980), "uma forma de capital social e que a sua realização e valorização tem maior importância estratégica para os grupos sociais e famílias cujos percursos são mais diretamente afetados pela falta de providência do Estado" (Bourdieu, 1980: 67).

A contradição entre o Estado providência e sociedade providência é, no primeiro caso, a dicotomia entre igualdade/segurança, cidadania/burocracia, cidadãos/clientes, bem-estar/feiticismo da mercadoria. Na senda de Boaventura Sousa Santos (1991), não podemos deixar de referir que os serviços oferecidos pela sociedade providência, não são os mesmos que o Estado oferece, pois funcionam em lógicas de mercado diferentes. E, neste sentido, o autor alerta para que, segundo a investigação sobre a sociedade providência, esta é avessa à igualdade, ou pelo menos não distingue tão bem quanto o Estado entre desigualdades (legítimas e ilegítimas); é hostil à cidadania e aos direitos pela complexidade e arbitrariedade dos atos de boa vontade; cria dependência e formas de controlo social (mais flexíveis e negociáveis); tende a criar rigidez espacial e para que o bem-estar social recaia nas mulheres pelos hábitos familiares e sociais dominantes.

Assim, conclui, "em termos analíticos e políticos é fundamental distinguir entre combinações progressivas e combinações regressivas, mas (...) a discussão, embora bemintencionada, não conseguiu ainda estabelecer, de modo claro, essa distinção (...)" (Santos, 1991: 49). Em Portugal, as políticas de inclusão servem para aliviar a severidade das 
desigualdades na sociedade, o confronto entre solidariedade e justiça social e entre a procura de competitividade e eficiência, o que é deveras inquietante em relação à pobreza.

Nas sociedades modernas ocidentais, pobreza e exclusão são dois conceitos que se reforçam e alimentam mutuamente. Ou seja, de acordo com Rodrigues et al . (1999)

a exclusão do mercado de trabalho gera pobreza e esta impede o acesso a bens e serviços socialmente relevantes (habitação, saúde, lazer). Um excluído será aquele que não consegue configurar uma identidade (social) no trabalho, na família ou na comunidade. Tornando-se um excluído das relações sociais e do mundo das representações a elas associadas. Assim, "os excluídos não constituem uma ordem, uma classe ou um corpo. Eles indicam, antes, uma falta, uma falha do tecido social (Rosanvallon, in Rodrigues et al 1999: 66).

\section{Considerações finais}

$\mathrm{O}$ envelhecimento da população e consequente longevidade impõem novos desafios à sociedade na contemporaneidade, da qual não nos podemos abster, pois envelhecer é um dado natural, sendo necessário e urgente uma reflexão alargada sobre este tema.

As manifestações de envelhecimento são entendidas de forma diferente pelos indivíduos e surgem em combinações variadas e em idades distintas, conferindo ao envelhecimento uma marca individual, pelo que se torna inútil definir uma idade concreta para o seu início.

A velhice como um período socialmente considerado de declínio, constitui ainda uma fase do desenvolvimento humano. Devendo esta perspetiva contrariar a visão social das pessoas de idade avançada, contrariando o Idadismo (preconceito etarista) dado que este se traduz em pré-conceitos que conduzem, através de uma atitude valorativa, à discriminação de pessoas, no caso específico pela sua idade.
A categoria social destas pessoas não é homogénea e está afastada da realidade, uma vez que cada indivíduo tem uma história de vida, determinada pelo seu património genético e psicossocial, é uma pessoa que contribuiu para a sociedade e que se mantém em sociedade reforçando uma atitude cívica, uma consciência Social. As pessoas de idade avançada, com projetos existenciais, continuam ativas e integradas na sociedade, para além da imagem biótica, das imagens relacional, auto e héteropessoal, e estão integradas em sociedade com voz, vontade e veto-Cidadania.

Empiricamente, a velhice tende a ser concebida com a atribuição de caraterísticas negativas cuja apreciação encaixa numa visão estereotipada sobre os indivíduos com mais de 65 anos. No entanto, as mudanças nos discursos políticos e uma maior preocupação com as políticas sociais para as pessoas de idade avançada, com base na maior longevidade humana, têm esbatido esses estereótipos, ainda presentes no senso comum, embora denunciando um olhar sobre a velhice menos negativo.

Cada vez mais é necessária a criação de mecanismos que envolvam e garantam a estas pessoas o lugar a que têm direito na sociedade e principalmente que garantam o exercício da sua cidadania. Pois são pessoas/ cidadãos que existem no tempo e no espaço, possuidores de sentimentos, pensamentos, perceções, necessidades e interesses, com direitos e deveres, como qualquer outro cidadão.

\section{Referências}

Beauvoir, Simone (1990). A Velhice. Rio de Janeiro: Nova Fronteira.

Bourdieu, Pierre (1998). Meditações Pascalianas. Oeiras: Celta Editora.

Bourdieu, Pierre (2001). O capital social: notas provisórias (1980). In: NOGUEIRA, Maria Alice; CATANI, Afrânio (Orgs.) Escritos de educação (3). Petrópolis: Vozes, pp. 6569.

Costa, Alfredo Bruto (2005). Exclusões

Sociais. Cadernos democráticos. pp. 11-85. Lisboa: Gradiva. 
Estevão, Carlos Alberto V. (1997). Cidadania organizacional: o enquadramento institucional de um conceito para uma alternativa pós-moderna da cidadania. Cadernos do Noroeste, 10(1). Recuperado de https://dialnet.unirioja.es/servlet/articulo?cod igo=2762219.

Fernandes, António T. (1995). Etnicização e racização no processo de exclusão social. Recuperado de http://ler.letras.up.pt/uploads/ficheiros/1381. pdf.

Fonseca, António M. (2006). A Noção de idade e o Idadismo. In: $O$ Envelhecimento: Abordagem Psicológica (2). Lisboa: Universidade Católica Portuguesa, pp. 22-33.

Giddens, Anthony (1990). The consequences of modernity. Cambridge: Cambridge Polity Press.

Giddens, Anthony (1992). Modernidade e Identidade Pessoal. Oeiras: Celta.

Karsz, Saul (1988) (1). Deconstruire la Veillesse. Les Chaiers de la Recherche sur le Travail Social (15). Caen: Presses universitaires de Caen.

Lenoir, Remi (1989). Objeto Sociológico e Problema Social. In: MERILLÈ et al. Iniciação à prática sociológica. Trad. J. de Teixeira. Petrópolis, Rio de Janeiro: Vozes.

Macedo, Eunice (2009). Cidadanias em confronto Educação de jovens elites em tempo de globalização. Porto: CIIE LIVPSIC.

Marshall, Theodore H. (1967). Cidadania, Classe social e Status. Rio de Janeiro: Zahar Editores.

Oliveira, José H. Barros de (2010) (4). Psicologia do Envelhecimento e do Idoso Portugal: LivPsic.

OMS: Organização Mundial de Saúde (2002). Active Ageing: a policy framework. Geneva: World Health Organization.

OMS: Organização Mundial de Saúde (2015). Relatório Mundial de Envelhecimento e Saúde: United States of America

Paugam, Serge (2003). A Desqualificação Social: Ensaio sobre a nova pobreza. Porto: Porto Editora.

Perrenoud, Philippe (2005). Escola e Cidadania - O Papel da Escola na Formação para a Democracia. Porto Alegre: Artmed.
Quivy, Raymund, \& Campenhouldt, Luc Van (2008). Manual de Investigação em Ciências Sociais. Lisboa: Gradiva.

Rodrigues, Eduardo V., Samagaio, Florbela M. da S.,Ferreira,Helder, Mendes, Maria M. F., \& Januário, Susana P. C.(1999). A pobreza e a Exclusão Social: Teorias, Conceitos e Políticas Sociais em Portugal. Recuperado de https://repositorioaberto.up.pt/handle/10216/8578.

Saint-Maurice, Ana (1997). Identidades Reconstruidas: cabo-verdianos em Portugal.Oeiras: Celta Editora.

Sacristän, J. Gimeno (2003). Educar e Conviver na Cultura Global. Coleção perspetivas atuais: Educação. Edições Asa.

Santos, Boaventura S. (1997). Por Uma Conceção Multicultural de Direitos Humanos. Revista Crítica de Ciências Socais,(48), Junho de 1997. Recuperado de http://www.boaventuradesousasantos.pt/medi a/pdfs/Concepcao_multicultural_direitos_hu manos_RCCS48.PDF.

Squire, Anne (2005). Saúde e Bem-Estar para Pessoas Idosas: Fundamentos Básicos para a Prática. Loures: Lusociência.

Stoer, Stephen, Magalhães, António, \& Rodrigues, David (2004). Os Lugares da Exclusão Social. Um dispositivo de diferenciação pedagógica. São Paulo: Cortez Editora.

Stoer, Stephen, \& Magalhães, António(2005). «A Diferença Somos Nós» - A Gestão da Mudança Social e as Políticas Educativas e Sociais. Porto: Edições Afrontamento.

Stoer, Stephen (2008). Novas Formas de Cidadania, a Construção Europeia e a Reconfiguração da Universidade. Revista:Educação, Sociedade \& Culturas, (26), pp. 219-238.

Dados sobre as autoras:

- Isabel Maria Gomes de Oliveira, Licenciada em Ciências da Educação pela Faculdade de Psicologia e de Ciências da Educação da Universidade do Porto, Pós- Graduada em Administração Pública e Políticas Públicas pela Universidade Aberta de Lisboa, Mestre 
em Ciências da Educação domínio Educação de Adultos e Desenvolvimento Local pela Faculdade de Psicologia e de Ciências da Educação da Universidade do Porto e formadora certificada pelo Instituto do Emprego e Formação Profissional.

- Maria da Luz Cabral nasceu no Porto, Licenciada em Ciências da Educação pela Faculdade de Psicologia e de Ciências da Educação da Universidade do Porto, PósGraduada em Psicogeriatria no Instituto CRIAP - Psicologia Avançada, Mestre em Ciências da Educação domínio Intervenção Comunitária pela Faculdade de Psicologia e de Ciências da Educação da Universidade do Porto, doutoranda em Psicologia na Faculdade de Psicologia e de Ciências da Educação da Universidade do Porto, na área do Envelhecimento, preparação para a reforma e Solidariedade Intergeracional. Formadora na Faculdade de Psicologia e de Ciências da Educação da Universidade do Porto - Serviço de Educação Continuo, em organizações sindicais e equipamentos sociais, certificada pelo Instituto do Emprego e Formação Profissional e pelo Conselho Cientifico e Pedagógico de Formação Continua do Ministério da Educação. Orientadora diversos estágios académicos e profissionais, júri de provas de aptidão profissional. É Coordenadora do Departamento de Política e Trabalho Social da Escola Superior de Saúde do Alcoitão (ESSA). PhD Student Programa Doutoral em Psicologia Social e das Organizações no ISCTE - Instituto Universitário de Lisboa com projeto de tese "Design de políticas sociais: Determinantes psicológicos do "non take-up" na era da governação digital e virtual ". Mestre em Ciência da Educação, domínio da Intervenção Comunitária, tese "Envelhecimento: Perspetivas, Representações e Solidariedade Intergeracional" pela Faculdade de Psicologia e de Ciências da Educação da Universidade do
Porto (FPCE-UP). Pós-graduação em Psicogeriatria pelo Instituto CRIAPPsicologia Avançada. É Professora responsável pelas unidades curriculares de "Sociedade, saúde e Doença" e "Organização e Gestão" no âmbito das licenciaturas da ESSA. Organiza mensalmente um ciclo de conferências de pertinência e atualidade na ESSA. 